\title{
Questioning the assumption of universality in psychiatric approaches to mental healthcare in Canada
}

\section{Rowan El-Bialy}

\author{
Memorial University
}

Mental health services in Canada are primarily based on knowledge gained in the fields of psychiatry and psychology. These fields have, in turn, emerged from a very specific cultural and historical, that is, English-speaking and Euro-American, context. Over the past thirty years, scholars in cross-cultural psychiatry have examined the applicability of western psychiatric approaches to mental health in other cultures. This body of research views the knowledge system of psychiatry as a product of the culture in which it has emerged, and demonstrates that it is neither universal nor applicable in other cultural contexts. In this paper, I will examine some of the arguments that scholars in this area have put forward, while considering the implications of this research for mental health services that serve ethnolinguistic groups in Canada.

In the 1980s, Arthur Kleinman, a psychiatrist and anthropologist, argued that psychiatry is a product of western culture, and thus psychiatric categories and treatments are specific to that culture, and not universally valid. He conducted research in Asia to investigate how culture influences how one perceives mental health and illness. ${ }^{1}$ He argued that the biomedical view of mental illness as an individual matter emerges from a uniquely western worldview, and although it makes sense to those immersed in that culture, it cannot be extrapolated to other cultures and worldviews. ${ }^{1}$ Since then, a robust body of research has emerged that has identified several characteristics of the psychiatric approach to mental health which limit its applicability in other cultures. Two such characteristics are: the biomedical basis of psychiatry and the emphasis on mental health as an individual affair. I will briefly discuss how these two characteristics have been problematized in the literature.

Western psychiatry is undoubtedly built upon the biomedical model that underlies western medicine. ${ }^{1}$ A good example of this is the Diagnostic and Statistical
Manual (DSM)'s categorization of mental illness in terms of 'diseases' and 'disorders'.2 Similarly, the biomedical nature of psychiatry is apparent in treatments for mental illness, which often rely on drug-based therapies. Although many accept this biomedical approach to diagnosing and treating mental illness, others who view mental health through alternative cultural and knowledge lenses reject it. For example, in a study by Laura Simich and colleagues, ${ }^{3}$ members of five ethnolinguistic communities in Toronto expressed hesitation over using mental health services in Canada due to their relatively narrow, biomedical focus. One participant compared mental health services in Canada with those in Poland; the former focuses on ridding the individual of what is seen as a medical illness, while the latter focuses on rehabilitating the person physically, mentally, and spiritually through non-medical therapies. Similarly, scholars have argued that the medicalization of mental illness can trivialize the social problems that cause them. ${ }^{1,4}$ In one study, refugee women who were interviewed about feeling depressed said that mental health 'treatments' should not target their individual psyches, but the structural inequalities leading to their distress. ${ }^{5}$ These examples demonstrate how the biomedical approach to diagnosis and treatment of mental health problems limits its compatibility with alternative understandings of mental health.

The psychiatric approach to mental health is not universally applicable for another reason: it focuses almost exclusively on the individual as a locus of diagnosis and treatment. ${ }^{6}$ In many social contexts, however, a person's identity is not experienced so much as an individual identity, but as a part of a collective or a group. ${ }^{7}$ In such cases, the individualized psychiatric approach to mental health would be inappropriate because it does not address the social causes of mental health problems either in diagnosis or treatment. ${ }^{5,6}$ In response, alternative approaches to mental health have been developed that focus on promoting 
community mental health, with particular attention to social experiences that are shared among community members and impact their mental wellbeing. ${ }^{6}$ Such programs seek to strengthen the community's existing networks and sources of resilience, as well as addressing social inequalities that make community members vulnerable to mental health problems. Community mental health promotion projects have been successfully used in different types of communities, such as groups of immigrant and refugee women from diverse cultural backgrounds, ${ }^{8}$ as well as communities recovering from tragic events. ${ }^{9}$

Although many people who suffer from mental health problems find the western psychiatric approach to diagnosis and treatment beneficial, this approach is not universally applicable to people who have alternative understandings of mental health. Alternative knowledge of mental health can be found amongst diverse ethnocultural groups, who may hesitate to use current mental services because they are not compatible with their own understandings of mental health. In a country as diverse as Canada, it is critical for policy makers and service providers to acknowledge alternative ideas about mental health, in order to develop services that do not systematically exclude ethnocultural members of the population. Greater effort should be made to learn about alternative understandings of mental health, without automatically recoursing to the categories and treatments of mental illness created by western psychiatry.

\section{References}

1. Kleinman A. Rethinking psychiatry: From cultural category to personal experience. Free Press, Macmillan Publishing: New York; 1988.

2. American Psychiatric Association. Diagnostic and statistical manual of mental disorders (4th ed.). Washington, DC: Author; 1994.

3. Simich L, Beiser $M, \&$ Mawani F. Social support and the significance of shared experience in refugee migration and resettlement. West J Nurs Res. 2003; 25: 872-891.

4. Mulvaney J. Medicalization, marginalization and control. In Waddell $\mathrm{C}$ and Petersen A, editors. Just Health. Melbourne: Churchill Livingstone; 1994.

5. Tilbury F \& Rapley M. 'There are orphans in Africa still looking for my hands': African women refugees and the sources of emotional distress. Health Soc. Rev. 2004; 13: 54-64.

6. McCabe A. Community development as mental health promotion: principles, practice and outcomes. Comm Dev J. 2012; 47(4):506-521.

7. Haj-Yahia M. Contextualizing interventions with battered women in collectivist societies: issues and controversies. Agress Viol Behav. 2011; 16: 331-339.

8. Wong YR, Wong JP, Fung KP. Mental health promotion through empowerment and community capacity building among east and southeast Asian immigrant and refugee women. Can Iss. 2010;108.

9. Austen P, Health Canada. Community capacity building and mobilization in youth mental health promotion: the story of the community of West Carleton: how the Community Helper Program evolved from a community's experience with youth suicide. Ottawa; 2003.

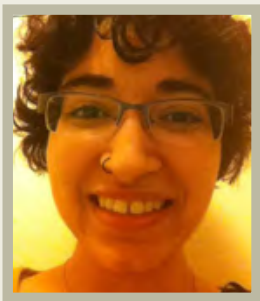

\section{Rowan El-Bialy}

Rowan is completing an MSc in Medicine (Community Health and Humanities) at Memorial University of Newfoundland. Her thesis project is titled, "The influence of gender and culture on the mental health of refugees in St. John's." Rowan's research interests include collectivist and individualist notions of mental health, the impact of gender and cultural identity on coping and resilience, and the social determinants of mental health. 